\title{
Contraponto brasileiro no tempo da dança
}

\author{
Inês Bogéa
}

dança contemporânea tem um forte aspecto multidisciplinar. Com freqüência cada vez maior, exploram-se áreas muito diversas para orquestrar a força expressiva dos corpos. Em sintonia com isto, a dança brasileira como um todo recusa qualquer ilusão de unidade, o que não significa que seu alcance não seja maior quanto mais assume suas particularidades. E sua força parece proporcional ao poder de infiltração nas brechas da nossa cultura.

A famosa variedade cultural do Brasil se revela de maneira sistemática na dança. Se o seu sentido pode variar de acordo com as escolhas de cada um, reagindo às ambigüidades da noção de uma identidade brasileira, não deixa de ser fato que aos olhos de um estrangeiro o Brasil possui algo de imediatamente reconhecível, em que pesem todas as suas diferenças (regionais, raciais, culturais). Como diz o crítico inglês Donald Hutera, sintetizando uma visão comum, "a dança brasileira [...] possui um ritmo que a singulariza. A distinção é baseada em parte pelo movimento dos quadris e o uso dos braços. Mas o maior campo de diferença está na cultura brasileira, com seu clima quente, sua inata musicalidade e sua mistura racial". ${ }^{1}$
Mas quando começa isso que agora é a dança "brasileira"? Foi a partir da década de 1970 que se deu uma significativa mudança de foco; a dança se voltava agora, em especial, para questôes da identidade. Nesse momento surgiram, entre outros, o Balé Stagium - um dos primeiros a falar de questóes brasileiras na dança -, o Cisne Negro - que daria espaço a uma multiplicidade de coreógrafos brasileiros e internacionais - e o Grupo Corpo, que trabalha as brasilidades a partir de uma linguagem corporal particular. "O papel do artista criador não é figurar uma nacionalidade, mas transfigurá-la", já dizia o grande poeta e teórico modernista Mário de Andrade (numa carta ao compositor Camargo Guarnieri, de agosto de 1934). Ecoando essa idéia, nas décadas de 80 e 90 a dança no Brasil vem adquirir uma grande variedade de idiomas, que interagem criando novos campos de atuação.

Diversas vertentes estão presentes no cenário. Paralelamente à incorporação de novos conceitos (em diálogo direto com a cena internacional), o espaço cênico passou a ser explorado de outros modos e a dança também investiu na relação com as artes plásticas, ou incorporou

Inês Bogéa é crítica e professora de dança.

1 Dance Europe, Agosto de 2000. 
elementos nacionais, com música de compositores brasileiros contemporâneos; ou ainda, buscou apoio na literatura, ou se valeu da associação com o teatro. $\mathrm{Na}$ variedade que marca a produção atual, também estão presentes elementos da cultura popular urbana: break dance, hip hop e outras linguagens são acolhidas e transformadas; efeitos tecnológicos de imagem, luz e som passam a ser mais utilizados nos espetáculos. Por outro lado, há um interesse pelas danças de outras culturas e pelas artes marciais, voltadas para atitudes metafísicas, muitas vezes como forma de resistência ao excesso de informação. É o caso da minimaldance, com repetições de seqüências de movimento, em inúmeras combinações.

Ao contrário do que pode parecer à primeira vista (pela pressão dos movimentos e pulsões expressivas "brasileiras"), produzir arte, para os novos grupos, vai significar, cada vez mais, uma expansão dos limites do objeto e uma geração de obras mais complexas do ponto de vista conceitual. As apostas agora engajam rotineiramente o plano intelectual e reflexivo. É neste momento que são criados alguns grupos que ganharão renome internacional, como a companhia Quasar, a Deborah Colker e a Lia Rodrigues.

$\mathrm{O}$ adensamento do meio artístico propicia também um desenvolvimento profissional notável, marcada por novas possibilidades de apresentação dentro e fora do Brasil. Com o mercado brasileiro ainda incapaz de absorver e garantir a sobrevivência dos artistas, dá-se um relativo êxodo em busca do cenário estrangeiro - benefi- ciando-se também do êxito de alguns nomes que já faziam parte do repertório internacional da dança, como Ismael Ivo e Regina Advento. ${ }^{2}$

No texto abaixo, a partir de uma análise corpo a corpo de determinadas obras, procuraremos estabelecer relações que ampliem o significado da produção de dança brasileira. A proposta é ver onde se dá a especificidade na nossa dança contemporânea e verificar seu alcance na cena internacional. Deve-se ter em mente que um corpo sempre se posiciona e responde ao mundo de modo particular. Portamos marcadores ambíguos e multifacetados de identidade: na cor da pele, no gênero, na idade, nas habilidades apreendidas e outras tantas marcas sociais. A recepção da dança brasileira no exterior, portanto, não será uma questão que surge de fora para dentro: melhor compreendê-la como um dos modos de decantação da própria dança em seus elementos.

\section{0 corpo do corpo}

A capacidade de fundir e adaptar estilos das mais variadas fontes é, quase paradoxalmente, uma das características mais originais do mineiro Grupo Corpo. A gestualidade mais típica de seu coreógrafo, Rodrigo Pederneiras, trabalha a sobreposição de formas, cunhando nos corpos uma existência insólita. Mas é da relação entre as diversas artes - música, cenário, iluminação e figurino - que se faz realmente a marca do Corpo. ${ }^{3}$ Todos esses elementos reunidos fazem das peças

2 Ismael Ivo - verdadeiro pop star na Alemanha - guarda influências que vão de raízes afro-brasileiras ao expressionismo de Pina Bausch, do radicalismo estético do diretor teatral Johann Kresnik ao butô do Sankai Juku. Paralelamente a seu trabalho de bailarino, ele atua como diretor de festivais na Europa, incluindo The International Tanzwochen e a Bienal de Viena e o festival do Deutsches Nationaltheater, em Weimar. E Regina Advento, bailarina do Grupo Corpo até 1990, atua há mais de dez anos na Tanztheatre Wuppertal, dirigida por Pina Bausch.

3 A partir de 1992, as partituras musicais são feitas especialmente para o Corpo por compositores contemporâneos - Tom Zé, Zé Miguel Wisnik, João Bosco, Arnaldo Antunes, Marco Antônio Guimarães (do grupo Uakti). 
do grupo quase um gênero particular da cultura brasileira da atualidade. Uma interrogação de ordem geral sobre espaço, tempo e movimento subdivide-se progressivamente em relações complexas entre interior e exterior, que engajam a seu modo questôes da atualidade do país.

Segundo Rodrigo Pederneiras "[o trabalho do Corpo] tem um tipo de linguagem muito particular, que envolve o jeito de ser brasileiro ou, no mínimo, de abaixo da linha do Equador - um modo mais sensual de ser e de explorar a dança”. ${ }^{4}$ Essa marca dos movimentos dos corpos, hoje tão reconhecida e valorizada, veio da sedimentação lenta de um jogo entre superfície e profundidade, entre verticalidade e horizontalidade, que parte dos passos clássicos em direção ao arqueamento, à torção e amplificação das possibilidades do gesto.

"O maior cumprimento feito a eles é o uso que fazem de material étnico e folclórico, e como o transformam em dança contemporânea”, escreve Eliyakim Yaron (Ma'ariv, 23/05/ 1999); para Sarah Kaufman (Washington Post, 23/07/1999) "a companhia criou sua própria forma híbrida de dança inspirando-se nas numerosas danças sociais de sua terra natal e estilizando-as com toques do ballet clássico [... seja] nas linhas alongadas e formas revigorantes, seja no seu swing malemolente e vertiginoso"; e para Anna Kisselgoff (New York Times, 26/10/2002), "energia é sinônimo de Grupo Corpo, a incansável e admirável companhia brasileira”. Se essas frases - como as de tantas outras resenhas estrangeiras - não dizem muito para uma audiência brasileira, porque não chegam a trabalhar a especificidade do Corpo, no contexto geral da nossa dança, elas são bons exemplos do modo predominante de recepção dessa arte fora do país. E não deixam de ter sua essencial verdade - coisa que o próprio grupo precisou descobrir aos poucos, até consolidar um estilo.
Foi com 21 (1992) que se deu uma virada na dança moderna brasileira, em direção de uma dança propriamente nossa, sem ser exótica, nem folclórica. Ela se volta para impulsos do corpo relacionados, em alguma medida, às danças e festas populares e ao movimento de rua. Se algo mudou dos idos de 70 para cá, foi a transformação na linguagem dos movimentos. Antes se falava das questões brasileiras através de gestos mais estilizados do balé; desde o final dos anos 80 o que se vê é um voltar-se sobre si mesmo, quebrando linhas e organizando as formas em grupo e pelo fluxo dos gestos. O movimento tende a se iniciar nos quadris para reverberar por todo o corpo, sem artifícios ou formas feitas.

A primeira parte de 21 tem um caráter mais introspectivo e vanguardista; ela deságua na segunda, explosiva, sem tempo ou espaço definidos, ampla e visceral. Aquilo que inicialmente era da sombra passa a mostrar sua luz, conquistando de súbito um colorido forte e, sem aspas, brasileiro. E os movimentos acompanham a divisão por dentro - o mesmo gesto contido do início ganha mais espessura e maleabilidade. Figura e o fundo se misturam numa espécie de estilhaçamento das coisas, pela intensa presença de gestos povoados de detalhes, em que cada parte do corpo responde a outra. A plasticidade rejeita uma formalização mais dura, deixando aparente um novo estilo tropical: 21 traz à tona as incongruências de um Brasil revisto de dentro, com toda sua ambigüidade. $\mathrm{O}$ tradicional e o moderno se cruzam, sem que haja propriamente uma solução; mas a resposta da dança é cheia de confiança.

A definição de uma identidade, vinculda a uma idéia de cultura nacional, estará presente nas múltiplas transformações do Grupo ao longo dos anos. Suas várias criações compõem um verdadeiro mapa emocional das culturas que

4 Entrevista à autora para a Revista OI, agosto 2004. 
formam o país. ${ }^{5}$ Nazareth (1994) toca em vertentes populares e eruditas, ao reunir a música de Ernesto Nazareth (1863-1934) e a literatura de Machado de Assis (1839-1908) na composição de José Miguel Wisnik, num cenário de rosas que alude ironicamente ao mundo das polcas e dos salóes. Bach (1996), uma adaptação musical de Marco Antônio Guimarães, nos leva de encontro ao barroco de Minas, com seus azuis e dourados dos cenários e figurinos, além dos tubos pendentes, que remetem ao órgão. Aqui também os gestos são mais largos, amplos e acentuados. Já o Nordeste vem nas curvas de Parabelo, de 1997, com música de José Miguel Wisnik e Tom Zé, um balé acentuado nos ritmos (xaxado, zabumba, baião) e no cenário, com figuras de ex-votos. A cultura afro-brasileira será vista em Benguelê (1998), em suas caminhadas infinitas e o movimento dos corpos mais próximos do chão, com marcadas influências da capoeira até a festa final nas cores do congado, festa típica das regiōes mineiras. Em contraste, O Corpo (2000) mostra um Brasil urbano, com sua violência e vigor, recriadas na música de Arnaldo Antunes - e num grande painel luminoso ao fundo. Assim era também Sete ou Oito Peças para um Balé (1994): uma dança sem território definido, onde os corpos que cruzam o palco coberto de verde parecem estar numa tela de computador. A música de Phillip Glass, com arranjos de Marco Antônio Guimarães, porta uma referência minimalista, também vista nos gestos. O balé mais recente, Santagustin (2002) traz a ironia e a sensualidade desbragada, por todos os cantos e de todas as maneiras. A música de Tom Zé e Gilberto Assis suscita novos ares, com seus coros das "mulheres pragmáticas", dos "homens-fêmeas", dos "sedutores egoístas" etc. Um gigantesco coração de pelúcia projetado em $3 \mathrm{D}$ no fundo do palco serve de emblema do que há de mais kitsch e ao mesmo tempo mais desabusado na nossa tradição sentimental.
A experiência proporcionada por estes trabalhos desafia a idéia do que é ser brasileiro, sem exotismo ou caricatura, embora baseada tão firmemente em raízes populares - material muito dado à caricatura, em especial quando visto de longe. O que o Grupo Corpo apresenta é um outro Brasil, que talvez só mesmo as formas da arte podem nos fazer ver. (E não são fáceis de decifrar.) Ao transformar certas matérias brutas do Brasil em dança, o Corpo nos devolveu a nós mesmos, para poder nos dar de novo, também, para o mundo.

\section{Aquilo de que somos feitos}

"Levantar ou tirar aquilo que cobria; revelar, inventar, descobrir segredos, dar a conhecer-se": são temas que perpassam a dança da Lia Rodrigues Companhia de Dança, criada em 1990 no Rio de Janeiro. A passagem incessante que se dá de um passo a outro, de um corpo a outro, gera uma linguagem na segunda potência: "o corpo tela, o corpo nu, o corpo social, o corpo casa”. A dança de Lia Rodrigues é como um manifesto de uma sociedade que se descobre pouco a pouco e que aprende a se organizar politicamente depois de longos anos de repressão, mas ainda vivendo num ambiente de desigualdade, miséria, fome.

O contexto não é um simples pano de fundo para se ver os movimentos da dança. Hoje mais do que nunca, as culturas são instáveis; seu trabalho procura resgatar pelo corpo a relação com o gênero, a raça e a identidade sexual, rompendo a tradicional visão de cultura nativa. Lia Rodrigues trabalha na fissura entre dois mundos - abstrato e literal - onde a dança pode mostrar suas identidades de muitas maneiras. $\mathrm{Na}$ sua atenção ao movimento físico há um interesse bem mais ambicioso do que toda a considerável ambição de mostrar como um corpo se move.

5 Esta idéia foi desenvolvida anteriormente em meu ensaio (Bogéa, 2001). 
Sua dança transita entre as artes sem fazer alarde. A dramaturgia permeia cada cena: na expressividade dos gestos, na configuração de cada parte, na relação de cada corpo no espaço e de cada corpo com o outro, ou com os objetos da cena. Por outro lado, o próprio corpo se transforma em escultura viva, renovando nosso olhar sobre o que é ao mesmo tempo tão cotidiano e tão distante de nós. O trabalho da coreógrafa porta uma intelectualidade intimista, sem ilustrar nenhuma teoria específica, mas repensando a seu modo as variadas situaçôes da nossa realidade.

Talvez por isso mesmo, as temporadas de sua companhia hoje são mais freqüentes na Europa do que no próprio Brasil; e alguns de seus trabalhos tem co-produção de produtores estrangeiros. Dominique Frétard (Le Monde, 29/ 09/2001) ao falar do seu trabalho toca num dos pontos cruciais, que é a capacidade de lidar com a falta e transformar a carência em algo a seu favor. $\mathrm{O}$ nu, elemento marcante nas peças de Lia, foi bem traduzido por Jochen Schmid (Frankfurter Allgemeine Zeitung, 02/08/2002): "apesar de toda a nudez, [suas peças] praticamente não denotam erotismo e nem muito menos sordidez: trata-se antes de uma demonstração arrebatadora e talvez única daquilo que o corpo é, e do que é capaz". Ou ainda, como diz Mary Brennan (The Herald, 24/10/2003): "Lia Rodrigues não faz provocações vazias. Seu objetivo é revelar verdades sobre identidade e comportamento por meio de uma consideração de corpos nus e vestidos".

Em Folia (1996), Rodrigues inspirou-se na literatura oral, a partir das obras do já citado escritor Mário de Andrade (1893-1945), para compor um espetáculo que unisse erudito e popular, sertanejo e urbano, moderno e arcaico. São divisões elementares e até hoje problemáticas da nossa cultura. Cada vez mais abertamente preocupada com os rumos do Brasil, a coreógrafa foi se aprofundando e ao mesmo tempo se despindo para montar Aquilo de que Somos Feitos (2000). Desde o preço do ingresso, tudo integra a simbologia do espetáculo: na estréia, cada entrada custava $\mathrm{R} \$ 1,99$ denunciando a "banalização e dessacralização" do corpo na sociedade, assim como da desvalorização do trabalho artístico. Slogans, grifes e nomes de cidades em guerra são recitados com indignação; cenas de morte e propagandas de grandes marcas se misturam, em corpos que são testemunha dos tempos. Buscou-se Portanto Falar a Partir Dele e não Sobre Ele (2002) foi encomendada pelo Culturgest de Portugal, para homenagear o professor da histórica escola multidisciplinar Bauhaus, Oskar Schlemmer (18881943); mais tarde viria a ser o espetáculo Formas Breves (2002). Além de Schlemmer, as Seis Propostas para o Próximo Milênio do escritor Italo Calvino (1923-85) foram outros pontos de inspiração. A "multiplicidade" calviniana de danças vai desde os movimentos mais comerciais do corpo feminino até grandes momentos da dança de rua, como o "break". Também o nu, continua forte aqui e cada vez mais natural - o nu, paradoxalmente, torna-se um figurino entre outros. A pele como segunda pele de si é uma das tantas ironias que teriam encantado Calvino. Parafraseando o autor, a coreografia "tem uma estrutura facetada", em que cada dança está próxima da outra, "formando uma rede dentro da qual se podem traçar múltiplos percursos".

Poderíamos dizer, parafraseando o crítico Roberto Schwarz, que "a matéria do artista não é informe: é historicamente formada e registra de algum modo o processo social a que deve a sua existência. Ao formá-la, o [coreógrafo] sobrepõe uma forma a outra forma, e é da felicidade dessa operação, dessa relação com a matéria pré-formada - em que imprevisível dormita a história - que vão depender profundidade, força e complexidade dos resultados. São relações que nada tem de automático....". 6 Se, para

6 Schwarz, 2001. 
Lia Rodrigues, arte "é para inquietar", é "uma reserva de contestação", "uma teoria viva do corpo vivo", 7 pode-se dizer que nesses corpos, tão concretos e tão expostos, em sua natureza e seus disfarces, a coreógrafa parece ter encontrado uma voz que não é só sua e que dá uma forma contundente à indignação dos nossos dias.

\section{A potência dos gestos}

A companhia Quasar faz uma dança de arrojo, num ritmo urbano. Para o coreógrafo fundador do grupo, Henrique Rodovalho, o Brasil que se vê na dança da Quasar vai além das referências diretas: "você ouve maracatu, embolada, forró e não vê o movimento que corresponde a essas danças. O que se vê é um olhar contemporâneo, influenciado por elas". ${ }^{8}$ Dança aqui é investigação e invenção: pelo corpo, vêm respostas e desafios para o entendimento do espaço coletivo.

Infinitas variações da espiral: como traçar uma linha de sombra persistente, como dobrar a questão da inumanidade do homem, como ser testemunha de um tempo, na ambivalência de toda apresentação. Música, dança e vídeo serão catalisados numa dramaturgia de gestos. O ponto de partida, assim, não vem da música e sim de uma idéia que organiza a cena; muitos gestos são criados no silêncio, para só depois se completarem na música.

A pluralidade e a habilidade técnica somada à inventividade fazem da Quasar quase um gênero distinto de dança brasileira: "Registro e Coreografia Para Ouvir surgiram para o público português como revelaçôes de um Brasil riquíssimo de sons e gestos, de música e movimento, e falante de uma linguagem artística plural, inteligente e atual" (Acarte, Lisboa, 07/ 2000). Outro exemplo: "Comediantes do corpo habilidosos e capazes de expressões faciais e corporais singulares, os nove dançarinos da Quasar se movimentam com vigor e ao mesmo tempo elegância, parecendo que ensaiaram tanto no campo de futebol como na academia de dança" (Jennifer Dunning, The New York Times, 19/10/1999). A referência ao futebol talvez incomode aos conterrâneos - como falar em Carmen Miranda, ou carnaval -, mas não é possível torcer o torcido e escutar ali, sem embaraço, o que de fato a dança faz dançar?

Criada em 1988, em Goiânia (centro oeste do país), a Quasar veio amadurecendo aos poucos a linguagem coreográfica de Henrique Rodovalho. Os movimentos da dança de rua são uma de suas fontes mais óbvias; mas a dança de rua é potencializada por ele em outra dança, onde a energia original explode em mil e um novos vetores. $\mathrm{O}$ vocabulário corporal é violento nos gestos que vão para o chão e se recuperam em fragmentos. Descontinuidades compõem um todo narrativo, onde convivem o que há de mais tradicional e simples confrontado com a sofisticação up to date. Os movimentos são feitos por impulsos de uma parte do corpo para outra, sem referência clara ao caminho traçado. O humor, em contraponto à dureza, é outra arma típica deste criador.

Em Coreografia Para Ouvir (2001), música e dança dialogam na sua essência, em contraponto a depoimentos de gente de rua. Não qualquer gente: nordestinos. Não qualquer nordestino: músicos, cantores, repentistas. "A música para mim... é tudo na minha vida"; "a vida é cheia de altos e baixos, com fome ou sem fome a gente tem é isso" - e a dança parte dessas palavras, que a seu modo já são música, no som e no sentido.

7 Programa do espetáculo Aquilo de que Somos Feitos.

8 Entrevista à autora para o jornal Folha de S.Paulo, 09/01/2003. 
O Brasil de dentro tem uma força que o Brasil de fora - o Brasil modernizado, bem aparelhado, urbanizado, repondo atrasos com sofisticação - nem sempre vê. Um espetáculo desses, feito de quase nada (um pano simples ao fundo, iluminado de vários modos, figurinos mínimos, trilha feita com gravador em punho) confere à dança um papel de mensageiro e renovador. E um coreógrafo como Rodovalho deixa evidente, desde o primeiro instante, o quanto não é só um coreógrafo: ele concentra em si todo um universo humano, que a gente conhece de novo como pela primeira vez. Talvez nisso também a Quasar tenha lições para nos dar: a matéria mais viva da dança não se entrega facilmente a nenhum de nós, desterrados fora e dentro do Brasil.

Explorando outro sentido do corpo, Empresta-me Teus Olhos (2002) perambula em dança, seja pelas ruas inóspitas de uma grande cidade, seja por uma comunidade de idosos, simbólica e literalmente nomeada Vila Vida. O chamado fica no limite do sentimental; mas a dança é um lastro e tanto para o espetáculo. É pelos olhos dos idosos que Rodovalho quer ver, agora, o mundo. E o mundo é visto na perspectiva realista e humana da morte. $O$ que não elimina o risco da emotividade fácil: traduzida em dança, leva a uma simplificação dos gestos. Mas o gesto final não tem nada de simples: corpos seminus, sentados de costas para a platéia, como uma dezena de Ingres, encarnando vida e morte nas formas vivas e mortas de uma obra que acaba.

Aqui se lida com o transitório e com a escassez, investigando o que o corpo pode e como se relaciona com o entorno. Gestar, justapor, aludir, duplicar, dar continuidade ao descontínuo: são questões que perpassam a arte brasileira da Quasar.

\section{Vigor e virtuosismo}

Deborah Colker conseguiu, em pouquíssimo tempo, criar um registro novo e popular para a dança no país. $\mathrm{O}$ virtuosismo do movimento se combina a seqüências atléticas, em cenários inusitados, onde o corpo parece superar os limites físicos da gravidade.

Velox (1995) tem uma enorme parede colorida e pontilhada, com pequenos suportes, nos quais os bailarinos se balançam, se penduram e giram. Rota (1997), que estreou em Nova York com grande sucesso, ecoa alguma coisa da dança atlética e espetacular de grupos americanos como o Momix e o Pilobolus. A imagem que predomina é a de uma roda gigante de 7,5 metros de diâmetro pesando uma tonelada e meia, emoldurada por escadas onde apresenta movimentos mirabolantes no mecanismo da vida diária. ${ }^{9}$ Já Casa (2000) busca o cotidiano em gestos estilizados. O cenário foi baseado na casa de Colker, com seus diferentes níveis, enquanto que os movimentos derivam de atividades domésticas: cozinhar, comer, dormir, vestir-se, despir-se, brigar, fazer sexo.

Criando novas densidades nos corpos e trabalhando com uma estética que une elementos de artes plásticas ao bric-a-brac do nosso diaa-dia, Colker provoca reações diversas em seus espectadores: se muitos se seduzem com o virtuosismo e o arrojo de suas danças, outros contestam a superficialidade das construções coreográficas e a "juventude" com que todos os temas são tratados, numa mistura de arte e diversão. Aqui sim, estamos num Brasil, afinal, alegre "um Brasil que nunca se cansa"10 -, nutrindose da sobreposição de registros: cultura pop, hip hop e rap, esporte e dança contemporânea. Colker transita entre as várias linguagens como se fosse a coisa mais natural.

9 "When the curtain falls, the audience's cheering isn't just a tribute to the dancers' extraordinary prowess, it's the sound of 1.000 people daring to breathe again" (The Guardian, www.barbican.org.uk/bite/ archive/bite03/issue3/show9_rota_press.htm).

10 Entrevista à Donald Hutera para a revista Ballet Tanz, abril de 2000. 
Em 4 por 4 (2003), os gestos interagem com o cenário, compondo formas que desafiam a gravidade e o tempo. Cenário e tanto: obras de Cildo Meireles, Chelpa Ferro, Victor Arruda e Gringo Cardia, que acolhem e desafiam os bailarinos, atualizando em grande estilo a visão de Colker da dança como espetáculo. Alguém dirá que o sentido se esgota nas formas; mas nem todos tomam isso por censura. Sara Kaufman (Washington Post, 13/10/2003): “O trabalho de Colker não se aventura muito abaixo da superfície. Mas o que se vê ali, no alto, é uma paisagem tão rica de cores que não é preciso escavar terreno algum". O controle do tempo permanece crucial para seu sucesso: cada quadro oferece uma surpresa e termina antes que a imagem se trivialize. Num desses quadros, o palco vai sendo preenchido por noventa vasos de Gringo Cardia, entre os quais vêm dançar os bailarinos, transformados em alegorias vivas do controle e da delicadeza. "Em 'Vasos', Colker nos dá aquilo que estávamos todos esperando. [...] O palco gradualmente se enche com 90 vasos de cerâmica dispostos em densas linhas diagonais. [...] Quem ficar procurando sentidos, ficará decepcionado", escreveu Jenny Gilbert, no Independent (14/12/2003).

É com espetáculos de rigor plástico e boa dose de aventura, apostando nas grandes imagens e no arrojo dos bailarinos, mais do que propriamente na invenção coreográfica, que Colker vem fazendo sua carreira de sucesso dentro e fora do Brasil. Sua dança encanta e empolga - dois verbos fortes, que merecem ser declinados com a devida medida de reconhecimento.

\section{Arremate: presenças do corpo brasileiro}

Combinando criticamente suas múltiplas raízes, seus hibridismos e mestiçagens, o corpo brasi- leiro tem se tornado presente mundo afora. $\mathrm{O}$ que não significa que esteja livre de simplificações, seja de caráter histórico, seja ideológico. Em especial, a idéia de uma "pureza brasileira" parece resistir até mesmo à relativa disseminação das obras de ensaístas brasileiros como Antonio Candido e Roberto Schwarz, para ficar só nesses - autores que nos dão instrumentos para compreender as formas da cultura para além de seu reconhecimento rápido em padrões de comercialização internacional.

Traduzindo da música para a dança o pensamento de Lorenzo Mammì, "o que faz a grandeza da [dança] brasileira não é a existência de uma linguagem nacional 'pura', mas a capacidade de fundir e adaptar técnicas e estilos das proveniências as mais variadas" (Mammì, 2002). E isso implicaria o reconhecimento também das influências externas - arcaicas, modernas e contemporâneas - sobre a nossa dança, em contraponto à valorização dos modos locais, em seu devido contexto, e com sua devida história de apropriações e desapropriações (um tema amplo, que não nos cabe comentar neste momento).

Que existe uma dança brasileira contemporânea fica claro, até pela resposta mais ou menos uniforme dos críticos estrangeiros a seus padrões gestuais expressivos. Se se apagam as diferenças, ressalta-se o que é comum - e não menos decisivo por isso. Que a dança brasileira informa até as sensações musculares, afinal, não deveria ser motivo de embaraço - nossa complexidade está inscrita e será constantemente reincorporada no corpo. A diversidade de vozes, as heterogeneidades, as linhas e torçôes na imagem da dança deixam mostras concretas de um mundo imediato ao redor. Ao mesmo tempo, evocam aquela esfera inalcançável, onde a dança brasileira quer chegar ao que é, em meio a tudo o que não é. 


\section{Referências bibliográficas}

BOGÉA, Inês. "O corpo: de lá para cá”. In: (org.), Oito ou nove ensaios sobre o Grupo Corpo. São Paulo: Cosac \& Naify, 2001.

MAMMİ, Lorenzo. "Prefácio". In: Cancioneiro Jobim - Antônio Carlos Jobim, Obras Escolhidas. Rio de Janeiro: Jobim Music, 2002.

SCHWARZ, Roberto. "As idéias fora do Lugar”. In: Cultura e Política. São Paulo: Paz e Terra, 2001. 